\title{
EU-Berufsausweis
}

\section{Vereinfachtes Anerkennungsverfahren für ausgewählte Berufe}

Noch sind die Zahnärzte nicht dabei, aber schon bald soll es auch für weitere medizinische Berufe möglich sein, einen europäischen Berufsausweis zu beantragen. Zukünftig soll das gesamte Annerkenungsverfahren, um in einem anderen Staat der Europäischen Union (EU) arbeiten zu können, elektronisch ablaufen. In der ersten Phase der Vereinfachung des Verfahrens ist diese Möglichkeit zunächst nur Krankenpflegepersonal, Apothekern, Physiotherapeuten, Bergführern und Immobilienmaklern vorbehalten. Laut der Vertretung der EU-Kommission in Deutschland soll das Verfahren in Zukunft auf andere Berufe ausgeweitet werden. Für Zahnärzte gelten die alten Regeln der Anerkennung zunächst weiter, wobei zu unterscheiden ist, ob es um eine Niederlassung in einem anderen EU-Land geht oder nur um eine vorübergehende Berufstätigkeit. Erkundigen sollten sich Interessierte immer über die Bestimmungen zur Anerkennung beruflicher Qualifikationen des Gastlands. Die Datenbank über reglementierte Berufe der EU informiert darüber, welche Berufe in welchen EU-Ländern reglementiert sind und welche Behörden zuständig sind.

sas

\section{Europäischer Gerichtshof lässt Klage zu Griechische Ärzte arbeiten zu lang}

Der Europäische Gerichtshof (EuGH) hat einem Vertragsverletzungsverfahren der EU-Kommission gegen Griechenland wegen der Nichteinhaltung der Arbeitszeitrichtlinie bei Ärzten stattgegeben. Dem Vertragsverletzungsverfahren ging eine Beschwerde

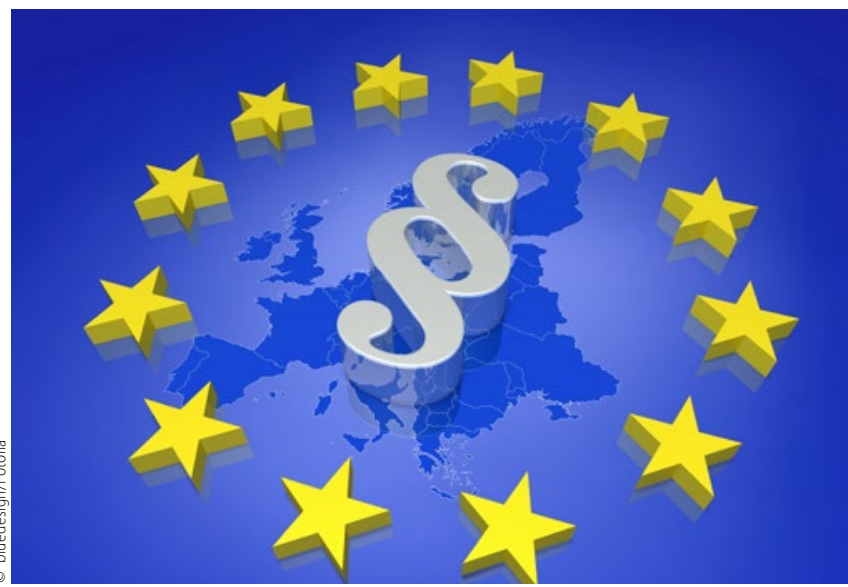

von zehn griechischen Ärzteverbänden voraus, die beklagten, dass Angestellte oder in Ausbildung befindliche Ärzte durchschnittlich 60 bis 93 Stunden pro Woche arbeiten müssen. Zudem betrage der Bereitschaftsdienst griechischer Ärzte bis zu 32 Stunden am Stück ohne Mindest- oder Ausgleichsruhezeiten.

Nach der Arbeitszeitrichtlinie darf die durchschnittliche Wochenarbeitszeit nicht über 48 Stunden hinausgehen und jedem Arbeitnehmer steht pro 24-Stunden-Zeitraum eine Mindestruhezeit von elf zusammenhängenden Stunden sowie pro Siebentageszeitraum eine kontinuierliche Mindestruhezeit von 24 Stunden zuzüglich der täglichen Ruhezeit von elf Stunden zu. Die EU-Kommission erarbeitet derzeit mit den europäischen Sozialpartnern, den Arbeitgeber- und Arbeitnehmerverbänden, eine Aktualisierung der gültigen Arbeitszeitrichtlinie.

Der EuGH hat nun dem Vertragsverletzungsverfahren der EUKommission stattgegeben und festgestellt, dass Griechenland die einschlägigen Vorschriften der Arbeitszeitrichtlinie nicht umsetzt. Falls Griechenland dem Urteil nicht nachkommen und die Arbeitszeitrichtlinie entsprechend anwenden sollte, kann die EUKommission finanzielle Sanktionen beantragen.

Französisches Verfassungsgericht

\section{Sachleistungsprinzip als verfassungswidrig eingestuft}

Frankreichs nationaler Verfassungshof, das Pendant zum deutschen Bundesverfassungsgericht, hat die Pläne der französischen Regierung, das Kostenerstattungsmodell in der ambulanten Versorgung durch das Sachleistungsprinzip zu ersetzen, zunichte gemacht und als verfassungswidrig eingestuft. In der Begründung heißt es, dass der Staat Berufstätigen, die selbst keine Staatsangestellten sind, keine Methode zur Abrechnung vorschreiben dürfe. Nach erfolglosen Streiks und Massendemonstrationen hatten mehrere Ärzteverbände Klage eingereicht. Aus Sicht der niedergelassenen Ärzte bedroht das Sachleistungsprinzip ihren Status als Freiberufler, und sie befürchten den zunehmenden Einfluss der Kassen auf ihre Interessen. Zudem sei das Sachleistungsprin- zip bürokratischer und somit teurer als die bereits 1946 eingeführte Kostenerstattung. Frankreichs sozialistische Gesundheitsund Sozialministerin Marisol Touraine hatte sich vor zwei Jahren für das Sachleistungssystem ausgesprochen, weil es angeblich sozialer und gerechter als die Kostenerstattung sei. Das französische Krankenversicherungssystem beruht bisher darauf, dass die Kosten für medizinische Behandlungen zu einem Großteil von den Krankenkassen erstattet werden, bei den Versicherten jedoch immer ein gewisser Kostenanteil verbleibt. Die Erstattung der Beträge richtet sich nach der Art der Leistung. Diesen sogenannten Selbstbehalt kann der Patient über eine private Zusatzversicherung abdecken. 